\title{
Untranslated RNA
}

National Cancer Institute

\section{Source}

National Cancer Institute. Untranslated RNA. NCI Thesaurus. Code C26549.

The product of so-called RNA genes; a functional RNA represents the final product of a gene rather than a transient molecule that will be translated into protein. 